\title{
Allergy sensitization and asthma among 13-14 year old school children in Nigeria
}

\author{
Oluwole $\mathrm{O}^{1}$, Arinola $\mathrm{OG}^{2}$, Falade $\mathrm{GA}^{2}$, Ige $\mathrm{MO}^{2}$, Falusi $\mathrm{GA}^{2}$, Aderemi $\mathrm{T}^{3}$, Huo $\mathrm{D}^{4}$, Olopade $\mathrm{IO}^{1}$, \\ *Olopade $\mathrm{CO}^{1,6}$
}

1. The Center for Global Health Initiative, University of Chicago, Chicago, Illinois, USA

2. College of Medicine, University of Ibadan, Ibadan, Oyo State, Nigeria

3. Lafia Hospital, Ibadan, Oyo State, Nigeria

4. Department of Health Studies, University of Chicago

5. Center for Clinical Cancer Genetics and Global Health, Department of Medicine, University of Chicago

6. Departments of Medicine and Family Medicine, University of Chicago, Chicago, Illinois, USA

\begin{abstract}
Background: The prevalence of asthma and role of atopy in asthma among children has not been clearly defined in Nigeria. Objective: To determine the prevalence of asthma and investigate risk factors related to allergy sensitization among urban and rural school children in southwest Nigeria.

Methods: Validated ISAAC questionnaire was administered to 1736 high school children in randomly selected schools in rural and urban communities. Identified asthma cases were matched to controls. Allergy skin tests, blood eosinophil count, serum IgE and stool examination for parasites were performed. Dust samples from homes were also collected and analyzed for allergens.

Results: The prevalence of asthma was 7.5\% (95\% CI 6.0 to $9.2 \%)$ and $8 \%(95 \%$ CI $6.0-10.4 \%)$ in the rural and urban communities respectively . Risk factors for asthma included cigarette-smoking, cats in the home and family size. Eosinophil count $(109 / \mathrm{L})$ was elevated in asthmatics [0.70 (95\% CI 0.48-1.11) vs. 0.32 (95\% CI 0.19-0.69); $p<0.01]$, but IgE levels were similar between the two groups $(298 \pm 229 \mathrm{IU} / \mathrm{mL}$ vs. $288 \pm 257 ; p=0.97)$. Positive skin tests to cat hair, cockroach, mango blossom and mouse epithelium were more frequent in asthmatics than in healthy controls, especially in the rural communities. There was no correlation between allergens in dust collected from homes and skin test reactivity.

Conclusion: Asthma prevalence is similar in rural and urban children in Southwest Nigeria and atopy with elevated IgE was not observed to be a major factor for asthma in our cohort of children in both communities.
\end{abstract}

Key words: Asthma, risk factors, prevalence, atopy, sensitization, children

African Health Sciences 2013; 13(1): 144 - 153 http://dx.doi.org/10.4314/ahs.v13i1.20

\section{Introduction}

The prevalence and severity of asthma has increased among children worldwide, especially in urban and industrialized regions of the world ${ }^{1-2}$. Studies indicate that asthma and atopic conditions are less common among children in rural and less-developed countries $^{3-4}$. The reasons for the prevalence gradients are currently not well understood. Factors associated with Westernization such as lifestyle changes (modern housing, improved hygiene and sanitation and dietary changes) and environmental factors (allergen sensitization and air pollution) have been implicated ${ }^{3-}$ ${ }^{5}$. The increase in the prevalence of asthma and allergy
*Corresponding author:
Christopher O Olopade
The Center for Global Health Initiative
Department of Medicine
University of Chicago
Tel: 773-702-6479
Email: solopade@bsd.uchicago.edu

in susceptible individuals who have migrated from developing countries to developed countries underscores the importance of Westernization in the global increase in asthma prevalence ${ }^{6}$.

The observed differences in the expression and prevalence of asthma between developed and less-developed countries are consistent with the hygiene hypothesis, which suggests that exposure to pathogens early in life protects against the development of atopic phenotypes by contributing to immune system development ${ }^{7}$. While exposure may differ, the hygiene hypothesis cannot fully explain the pattern of asthma epidemic, especially the concomitant increase in the prevalence of asthma in poor-urban and rural communities in developed countries. Therefore, it is possible that other factors are likely involved.

In sub-Saharan Africa, early reports suggested that asthma was uncommon and not associated with 
atopic sensitization despite increasing prevalence of atopy $^{8-9}$. The low asthma prevalence has been attributed to the paucity of high quality data in some areas, chronic helminthic infection and a heightened regulatory response, which inhibits development of allergic diseases ${ }^{4,10}$. However, the suggested protection based on the hygiene hypothesis contrasts with other studies, which, suggests that the prevalence of asthma in African children is on the rise $\mathrm{e}^{11-12}$.

Rural and urban-poor children typically have more environmental and allergen exposures and are more likely to be sensitized to allergens such as house-dust mites and cockroach ${ }^{13}$. While sensitization to allergens may be present, reasons for the increasing asthma prevalence, especially in urban-poor and rural communities demand further investigation. Thus, the aim of this study was to evaluate the prevalence of asthma among 13-14 years old children and to investigate the relationship between sensitization to environmental allergens and the development of asthmatic symptoms in children living in urban and rural communities in southwest Nigeria.

\section{Methods}

The Institutional Review Board on Human Research at the University of Ibadan, Nigeria and the University of Illinois approved the research protocol, and parents or guardians of all participants provided written informed consent. Approval to conduct the study was also obtained from the Oyo State Ministry of Education, Ibadan, Nigeria.

\section{Study participants}

The study was conducted in two phases in three rural communities: Abanla, Eruwa and Igbo-Ora and one urban community: Ibadan, in southwest Nigeria. In the first phase, 1,086 students aged 13 and 14 years old were randomly selected from 16 high schools from the three rural communities using a crosssectional survey. Another 650 students were randomly selected from 10 high schools in Ibadan, for a total of 1,736. The age group 13-14 years was selected in accordance with the research protocol of the International Study of Asthma and Allergies among Children (ISAAC) that used two age groups: 6-7 and 13-14 years age. ${ }^{1}$ The older age group was used in this study to minimize study cost and to recruit students who can complete the questionnaires on their own, thus, eliminating the need to go into the communities to interview their parents or guardians. Over a 6-month period, we administered the validated ISAAC questionnaires in the English language to all students. The questionnaires were selfcompleted by the students. Eighty-nine students were identified as asthmatics based on questionnaire responses.

In the second phase, 85 asthmatics were age (within one year), gender and school locationmatched with 85 non-asthmatic controls who had negative responses to the same set of questions. All subjects then underwent, allergy skin testing to 8 groups of allergens, blood tests for total serum $\operatorname{IgE}$, total eosinophil count, eosinophil percentage and stool evaluation for ova and parasites. Dust samples from bedroom areas in the students' homes were also collected and analyzed for the presence of allergens. Pre-established exclusion criteria were treatment with antihistamine or oral corticosteroids within three months and presence of skin disease that may affect interpretation of the allergy skin testing. No subjects were excluded on the basis of these criteria. Seven children (4 asthmatics and 3 controls) also underwent these experimental testing, but they were not included because they could not be matched to each other based on the matching criteria.

\section{Written questionnaire}

The asthma questionnaire that was used includes questions on wheezing and cough symptoms, previous diagnosis of asthma, and questions on rhinitis and eczema. In addition, children were asked to provide information about their household cooking fuel, number of siblings, pets, their smoking habits and that of their parents.

\section{Blood sample}

Venous blood samples were collected from all subjects in $10 \mathrm{ml}$ Vacutainer EDTA tubes. All samples were processed at the Institute for Advanced Medical Research and Training (IMRAT) laboratory at the College of Medicine, University of Ibadan, Nigeria. Serum samples were frozen and stored at $-80^{\circ} \mathrm{C}$ until analysis was performed. Samples were analyzed for white blood cells, IgE, hemoglobin phenotype, eosinophils and G6PD status as previously described $^{14}$.

\section{Allergy skin testing}

Allergy skin test was performed using the Skintestor OMNI $^{\text {TM }}$ (Greer Laboratories, Inc., Lenoir, North Carolina) on the volar side of the forearm with standardized extracts of eight groups of allergens 
as we previously described ${ }^{14}$. Skin response was measured after 15 minutes, considering skin wheal diameter. Atopy was defined as a significant positive skin test reaction to at least one of the applied allergens if the diameter of the skin wheal was $>3 \mathrm{~mm}$, while a wheal diameter $<3 \mathrm{~mm}$ was defined as negative response to the applied allergens ${ }^{15}$. A $>3 \mathrm{~mm}$ wheal is a net wheal compared to the negative control.

\section{Household dust sample collection and analysis} Household dust specimens were collected from the living room area, sofa, top of children's mattresses and floor, where the children spend a lot of time. The sampling area and time for dust collection were all standardized with use of the same vacuum cleaner and dust collection device from Johns Hopkins Dermatology, Allergy and Clinical Immunology Reference Laboratory (DACI). The samples were collected and analyzed for the following allergens: dust mite Dermatophagoides pteronyssinus (Der p 1) and dust mite Dermatophagoides farinae (Der f 1); cockroach; Blattella germanica (Bla g 1 and Bla g 2); mouse urine protein and mold spores using procedures from $\mathrm{DACI}^{16}$. Only 58 homes of asthmatics and 18 homes of non-asthmatic controls were sampled due to consent and scheduling difficulties.

\section{Stool evaluation for parasites}

All subjects produced fresh stool samples that were examined at the parasitology laboratory at the University College Hospital, Ibadan for ova and parasites as previously described ${ }^{14}$.

\section{Data analysis}

Prevalence of asthmatic symptoms was calculated for rural and urban children, separately. Logistic regression models were used to examine risk factors for asthmatic symptoms. Odds ratio (OR) and 95\% confidence intervals (CI) were calculated from logistic regressions. Data from urban and rural were pooled but location was always included as an indicator variable in the logistic regressions. In the second phase of the study, asthmatics and their matched controls are compared using paired t-tests (e.g. WBC and IgE) or Wilcoxon sign-rank tests (e.g. eosinophil counts and percentage eosinophil) for continuous variables. Allergy skin reactions and stool parasitism were compared between the two groups using Wilcoxon sign-rank tests. Conditional logistic regression was used to analyze matched case-control data to estimate odds ratio and 95\% confidence interval. Because only a subset of subjects had dust allergen data, we compared dust allergens between the two groups using Fisher's exact tests and Wilcoxon rank-sum test. Spearman correlations were used to examine the relationship between IgE, eosinophil percentage, eosinophil counts, stool helminthes infection, allergy skin reaction and home allergen content. All statistical analyses were conducted with Stata 10.0 (College Station, TX). A p-value less than 0.05 was considered statistically significance.

\section{Results}

\section{Subjects}

One thousand seven hundred and thirty-six students from 26 high schools (both rural and urban) participated in Phase 1 of the study. Participation rate was $62.6 \%$ and $37.4 \%$ for students in the rural and urban communities respectively. Asthma prevalence was similar between the rural children $(7.5 \%$ : 95\% CI 6.0-9.2\%) and urban children (8.0\%: 95\% CI 6.0$10.4 \%$ ). Eight-five matched pairs of cases and controls were included in the second phase; 58 from rural and 27 from urban communities.

Risk factors for asthma and allergy sensitization Risk factors for asthma and allergy sensitization among high school children in both rural and urban communities are presented in table 1 . The mean number $( \pm \mathrm{SD})$ of older siblings was significantly higher in the asthmatics $(2.8 \pm 2.4)$ than in the control group $(2.2 \pm 2.0) ; p<0.003)$. The number of older siblings increased the risk of asthma symptoms of $14 \%$ (OR $1.14,95 \%$ CI 1.05-1.23; $p<0.001)$. The total number of siblings was also significantly different between asthmatics and control subjects (OR 1.14, 95\% CI: $1.07-1.22 ; p<0.001)$. A total of 382 children had cats in the homes and $43(10.1 \%)$ had asthmatic symptoms, compared to $6.9 \%$ in children without cats in home (OR 1.56, 95\% CI 1.06-2.30; $p<0.03$ ).

There were significant differences between the asthmatics and non-asthmatic controls in the type of fuel used for cooking in the homes. Children with home electricity had lower risk of asthma symptoms while children with gas as the only type of fuel and those who used biomass fuel in open fire indoors had higher risk of asthma symptoms (OR 3.55, 95\% CI, 1.49-8.46; $p<0.02$ ) and (OR 1.86, 95\% CI 0.84-4.10; $p<0.05)$, respectively.

Smoking by the students and their parents was associated with increased risk of asthma symptoms (OR 4.17, 95\% CI, 1.32-13.1; $p<0.02$ ) and (OR 2.81, $95 \%$ CI 1.46-5.40; $p<0.002)$, respectively. In the multivariate analysis, number of siblings, smoking, and fuel type remained statistically significant predictors for asthma symptoms. 
Table 1: Logistic regression analysis of risk factors associated with asthma in 13-14 year old high school children in Southwest Nigeria

\begin{tabular}{|c|c|c|c|c|}
\hline Risk factors & $\begin{array}{l}\text { Without } \\
\text { symptom }\end{array}$ & $\begin{array}{l}\text { With symptoms } \\
\text { (prevalence rate) }\end{array}$ & $\begin{array}{l}\text { Adjusted } \\
\text { OR }(95 \% \mathrm{CI}) *\end{array}$ & $p$-value \\
\hline \multicolumn{5}{|l|}{ Home fuel } \\
\hline Electricity only & 168 & $8(4.6 \%)$ & 1.0 (ref.) & \multirow[t]{5}{*}{0.04} \\
\hline Gas only & 106 & $18(14.5 \%)$ & $3.55(1.49-8.46)$ & \\
\hline Biomass fuel in open fire only & 414 & $36(8.0 \%)$ & $1.86(0.84-4.10)$ & \\
\hline Others & 731 & $60(7.6 \%)$ & $1.71(0.80-3.65)$ & \\
\hline Multiple ways & 143 & $9(5.9 \%)$ & $1.34(0.50-3.56)$ & \\
\hline \multicolumn{5}{|l|}{ Old siblings } \\
\hline Per sibling increment & & & $1.14(1.05-1.23)$ & \multirow[t]{4}{*}{0.001} \\
\hline No old sibling & 400 & $19(4.5 \%)$ & 1.0 (ref.) & \\
\hline 1-4 siblings & 962 & $84(8.0 \%)$ & $1.84(1.10-3.06)$ & \\
\hline $5+$ siblings & 215 & $28(11.5 \%)$ & $2.77(1.51-5.09)$ & \\
\hline \multicolumn{5}{|l|}{ Young siblings } \\
\hline Per sibling increment & & & $1.15(1.03-1.27)$ & \multirow[t]{4}{*}{0.01} \\
\hline No young sibling & 374 & $28(7.0 \%)$ & 1.0 (ref.) & \\
\hline 1-4 siblings & 1118 & $86(7.1 \%)$ & $1.03(0.66-1.60)$ & \\
\hline $5+$ siblings & 85 & $17(16.7 \%)$ & $2.68(1.40-5.13)$ & \\
\hline \multicolumn{5}{|l|}{ All siblings } \\
\hline Per sibling increment & & & $1.14(1.07-1.22)$ & \multirow[t]{4}{*}{$<0.01$} \\
\hline No sibling & 96 & $3(3.0 \%)$ & 1.0 (ref.) & \\
\hline 1-4 siblings & 940 & $63(6.3 \%)$ & $2.15(0.66-6.98)$ & \\
\hline $5+$ siblings & 541 & $65(10.7 \%)$ & $3.87(1.19-12.6)$ & \\
\hline \multicolumn{5}{|l|}{ Lorry pass through street } \\
\hline Never & 344 & $26(7.0 \%)$ & 1.0 (ref.) & \multirow[t]{4}{*}{0.06} \\
\hline Seldom & 550 & $42(7.1 \%)$ & $1.01(0.91-1.68)$ & \\
\hline Frequent & 262 & $35(11.8 \%)$ & $1.77(1.04-3.01)$ & \\
\hline Almost the whole day & 396 & $28(6.6 \%)$ & $0.94(0.54-1.63)$ & \\
\hline \multicolumn{5}{|l|}{ Cat in home, past year } \\
\hline Yes & 382 & $43(10.1 \%)$ & $1.56(1.06-2.30)$ & \multirow[t]{2}{*}{0.03} \\
\hline No & 1172 & $87(6.9 \%)$ & 1.0 (ref.) & \\
\hline \multicolumn{5}{|l|}{ Smoking status } \\
\hline Yes & 16 & $4(25.0 \%)$ & $4.17(1.32-13.1)$ & \multirow[t]{2}{*}{0.02} \\
\hline No & 1538 & $123(7.4 \%)$ & 1.0 (ref.) & \\
\hline \multicolumn{5}{|l|}{ Parent smoking } \\
\hline Yes & 55 & $12(17.9 \%)$ & $2.81(1.46-5.40)$ & \multirow[t]{2}{*}{0.002} \\
\hline No & 1490 & $116(7.2 \%)$ & 1.0 (ref.) & \\
\hline
\end{tabular}

*Adjusted for location (urban versus rural).

Blood tests in asthmatics and controls

Detailed results on blood tests in asthmatics and nonasthmatic children are presented in table 2. Apart from the eosinophil count, which was significantly higher in asthmatics relative to non-asthmatic controls $(p<0.001)$, all other blood test parameters were similar between the two groups and not statistically significant.

Table 2: Blood tests analysis in asthmatics and non-asthmatic control subjects

\begin{tabular}{llll}
\hline & Asthmatic $(\mathbf{n}=85)$ & Control $(\mathbf{n}=\mathbf{8 5})$ & $\boldsymbol{p}$-value \\
\hline WBC $\left(10^{3} / \mathrm{uL}\right)$, mean \pm SD & $6.3 \pm 1.9$ & $5.9 \pm 1.3$ & 0.14 \\
Eosinophil $\left(10^{\circ} / \mathrm{L}\right)$, median (IQR) & $0.51(0.30-0.90)$ & $0.30(0.19-0.60)$ & $<0.001$ \\
Eosinophil $(\%)$, median (IQR) & $2(1-3)$ & $1(1-3)$ & 0.78 \\
Total IgE $(\mathrm{IU} / \mathrm{L})$, mean $\pm \mathrm{SD}$ & $245(85-500)$ & $165(90-500)$ & 0.78 \\
\hline
\end{tabular}




\section{Allergy skin test and stool parasitism}

The results of the skin test reactivity to eight groups of allergens are shown in figures 1 and 2. In asthmatics, $73 \%$ were positive for at least one allergen, compared with $60 \%$ in non-asthmatic control subjects (OR $=1.71$, 95\% CI: 0.89-3.31; $p=0.11)$. Among the allergens tested, sensitivity to cockroach and cat allergens were the most common risk factors associated with current wheeze between the two groups of school children. Asthmatics had significantly higher proportion of positive skin reactions to cat hair (OR=2.00, 95\% CI: 1.00-4.00) and cockroach antigen $(\mathrm{OR}=2.00,95 \% \mathrm{CI}$ : 1.033.89) than non-asthmatic controls $(p<0.05)$. No significant differences were observed for other allergens. However, when the data from the rural and urban children were analyzed separately, sensitivity to cockroach, cat hair, mango blossom and mouse epithelia were associated with current wheeze among the rural children (figure $2 \mathrm{~A}$ ) while there were no significant differences observed among the urban children (figure $2 \mathrm{~B}$ ). Also, only $17 \%$ of asthmatics and $13 \%$ of controls had Ascaris lumbricoides in their stool $(p=0.34)$, while $5 \%$ of asthmatics and $4 \%$ of non-asthmatic controls had stool that was positive for hookworm infestation $(p=0.42)$. There were no significant differences in stool parasitism between the two groups.

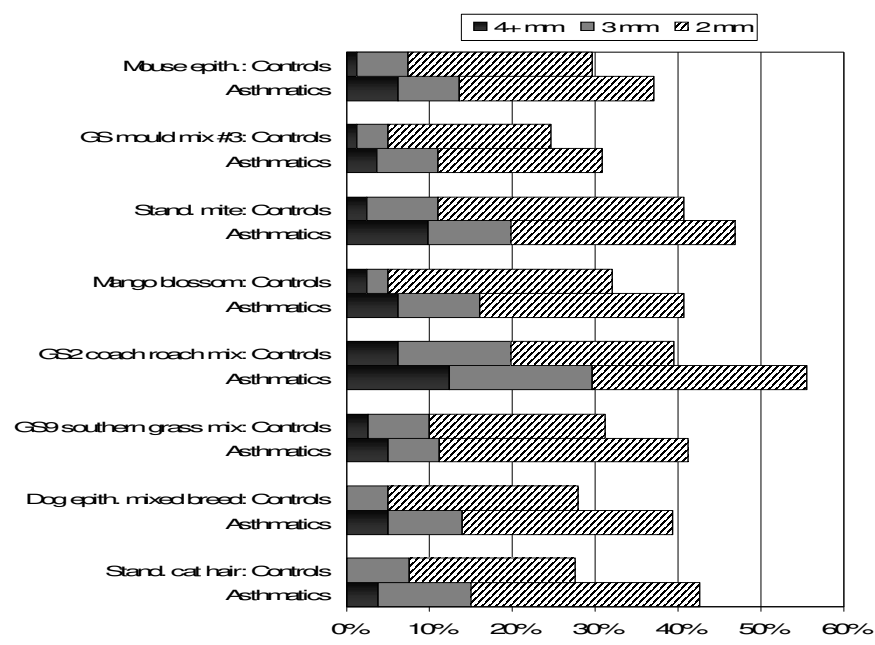

Figure 1: Percentage of positive skin test reactions to aeroallergens in asthmatics $(n=85)$ and nonasthmatic controls $(n=85)$
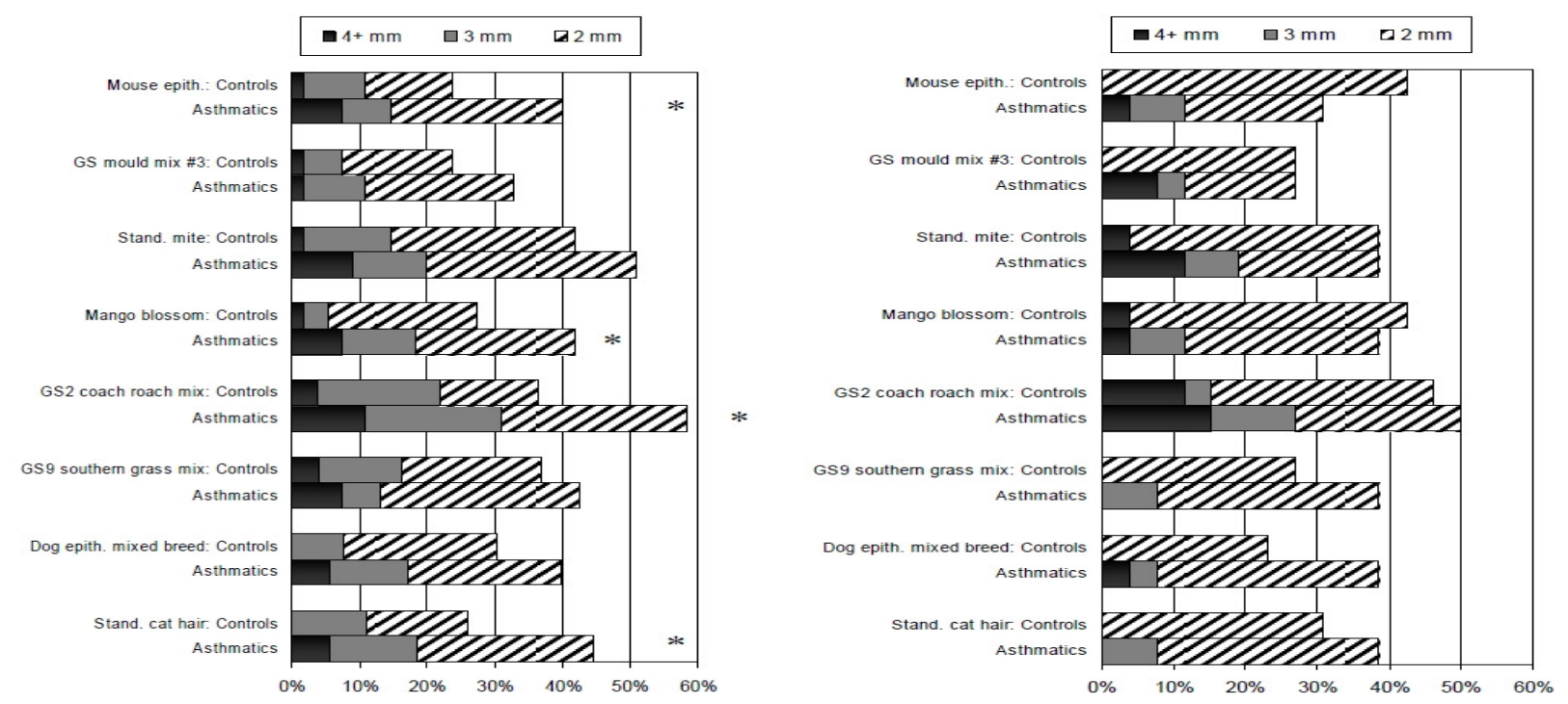

Figure 2: Comparative percentage of positive skin test reactions to aeroallergens

(A) Rural children: asthmatics ( $\mathrm{n}=58)$, non-asthmatic controls $(\mathrm{n}=58)(\mathrm{B})$ Urban children: asthmatics ( $\mathrm{n}=27)$, non-asthmatic controls $(\mathrm{n}=27)$ ${ }^{*} p<0.05$ 


\section{Home dust allergens}

Dust from households of 59 asthmatics and 18 nonasthmatic control subjects was sampled for environmental allergens. House dust mite Dermatophagoides farinae (Der $f 1$ ) and mouse urine protein were more likely to be detected in the homes of asthmatics, although no significant differences were observed between asthmatics and nonasthmatic controls for all tested allergens.

Table 3: Home dust allergens in children's indoor environment

\begin{tabular}{|c|c|c|c|c|}
\hline \multirow{2}{*}{$\begin{array}{l}\text { Allergens in dust } \\
\text { Dust mite Der } \mathrm{p} 1\end{array}$} & \multirow{2}{*}{ Asthma $(n=59)$} & \multicolumn{2}{|c|}{ Control $(n=18)$} & \multirow[t]{2}{*}{$p$-value } \\
\hline & & & & \\
\hline$<20 \mathrm{ng} / \mathrm{g}$ & 43 & 14 & & \\
\hline$>20 \mathrm{ng} / \mathrm{g}$ & 16 & 4 & $0.77^{\dagger}$ & \\
\hline Dust mite Der f 1 & & & & \\
\hline$<20 \mathrm{ng} / \mathrm{g}$ & 51 & 17 & & \\
\hline$>20 \mathrm{ng} / \mathrm{g}$ & 8 & 1 & $0.68^{\dagger}$ & \\
\hline Cockroach Blag g 1 & & & & \\
\hline$<1$ unit/g & 53 & & & \\
\hline$>0.4$ unit/g & 6 & 144 & $0.23^{\dagger}$ & \\
\hline Cockroach Blag g 1 & & & & \\
\hline$<1$ unit/g & 58 & 17 & & \\
\hline$>0.4$ unit/g & 1 & 1 & $0.42^{\dagger}$ & \\
\hline Mouse urine protein & & & & \\
\hline$<10 \mathrm{ng} / \mathrm{g}$ & 39 & 14 & & \\
\hline$>10 \mathrm{ng} / \mathrm{g}$ & 20 & 4 & $0.40^{\dagger}$ & \\
\hline Mold spores, CFU/g & & & & \\
\hline Median & 2200 & 3900 & $0.41^{*}$ & \\
\hline Interquartile range & $1000-6200$ & $1400-1$ & 300 & \\
\hline
\end{tabular}

Relationship between serum IgE, eosinophil percentage, eosinophil count, home dust allergens and stool helminthes infection

To identify potential risk factors for atopy, nonparametric Spearman correlation was used to examine the relationship between total serum $\operatorname{IgE}$, eosinophil percentage, absolute eosinophil count, home dust allergens, stool helminthes infection and the eight common aeroallergens. The data from the two groups were pooled. Dermatophagoides petronyssinus (Der $p 1)$ was significantly associated with absolute eosinophil count and eosinophil percentage $(r=-0.36$ and $\mathrm{r}=0.31$, respectively $p<0.05)$. Also, mouse urine protein level was significantly associated with eosinophil percentage $(r=0.27, p<0.05)$. Total serum $\mathrm{IgE}$ level was significantly related to a positive skin test only in response to cockroach antigen $(\mathrm{r}=0.23$, $p<0.01$ ). None of the stool parasites (A. Lumbricoides or Hookworm) showed any association with total serum $\operatorname{IgE}$, eosinophil count and eosinophil percentage.

\section{Discussion}

Early studies from developing countries have suggested that the prevalence of asthma is lower than in developed countries, and that the prevalence rates are much lower in rural communities relative to urban settings. ${ }^{5,17}$ In 1999 and 2004, the prevalence of childhood asthma in Nigeria was reported at $5.1 \%(18)$ and $7.2 \%(19)$, respectively. These reports were mainly from children living in urban settings. To our knowledge, this study is the first to determine the prevalence of asthma and evaluate the importance of sensitization to individual allergens for the development of asthma in both urban and rural schoolchildren in southwest Nigeria. It is also the first to address the role of environmental risk factors for asthma and allergy sensitization such as house dust allergens, total serum IgE and helminthic infection in addition to using the validated ISAAC questionnaire on which earlier studies were based. We observed an asthma prevalence of $7.5 \%$ in the rural communities, which was higher than one would have expected in such a setting. The prevalence in 
the urban setting was $8.0 \%$ and slightly higher than the $7.2 \%$ that was previously reported in the same geographical area in 2004. ${ }^{19}$ Although we did not perform indoor air quality monitoring for pollutants from the use of biomass fuel for cooking, we observed a significant difference in its use for cooking between rural and urban households (35.8\% vs. $11.3 \%$ respectively, $p<0.05)$. The use of biomass fuel for cooking was also more likely to be associated with asthma symptoms relative to the use of electricity in the homes we surveyed (table 1). Further research into the role of exposure to indoor air pollution from burning biomass and to second-hand cigarette smoke, either alone or in combination,on the increased asthma prevalence is needed, especially in rural communities. Exposure to allergens such as house dust mite, cockroach, cat and dog may result in the manifestation of asthma in sensitized children. ${ }^{20}$ High levels of cockroach allergen have been found to be associated with increased asthma prevalence in children in other geographical locations such as China and Ghana, especially in the inner cities. ${ }^{21-22}$ Our observations of development of allergic symptoms in relation to allergen exposure are also similar with these reports. In the rural and urban communities where this study was conducted, we observed that cats and dogs are commonly used for rodent control, especially in the rural communities, and tend to be less available as house pets, thus limiting their presence indoors. Sensitization to cat and cockroach allergens in the homes were major risk factors associated with current wheeze in the children. This is similar to observations in studies of 5- to 18-year old children that demonstrated that exposure and sensitization to cat allergen may be an important determinant of asthma hospitalization; ${ }^{23} \mathrm{cat}$ allergen is also regarded as the strongest independent risk factor for asthma in 12- to 14-year old children. ${ }^{24}$ However, sensitization to cats may have a variable response. For example, studies in the United States demonstrated that high exposure to cats was protective from asthma in some children, ${ }^{25}$ but it was a risk factor for its development in others, ${ }^{24}$ raising the possibility that individual responses may be variable and genetically mediated.

Other factors that contributed to asthma symptoms in our study include tobacco smoking, number of siblings, and birth order. Exposure to indoor and outdoor pollutants is known to contribute to asthma development or exacerbation. However, the incidence of asthma in children is more associated with exposure to allergens and pollutants such as smoke from biomass combustion and tobacco smoke in the indoor environment. ${ }^{26}$ Though it was relatively uncommon, we observed that smoking either by students or their parents was strongly associated with the risk of developing asthma symptoms. This corroborates reports suggesting that smoking and exposure to secondhand cigarette smoke and other inhaled allergens seem to shift the Th-1/Th-2 balance and may influence predisposition to Th- 2 associated respiratory diseases and increase the risk for IgE-mediated sensitization. ${ }^{27-28}$

Several population-based studies in developed countries have also demonstrated the presence of a sibling effect and importance of family size on atopic diseases. Low birth order, large family size and early daycare attendance in some studies have been described as having a protective influence on asthma in those who may be genetically predisposed, whereas others have not found this association. ${ }^{29-31}$ Contrary to these studies, we observed that birth order below five increased the risk for asthma symptoms by almost 300 percent. This is similar to findings from an urban cohort in Ghana where low $(<5)$ position in sibship was also an independent risk factor that increased asthma risk (OR, 3.6; 95\% CI, 1.18-11). ${ }^{21}$ According to the hygiene hypothesis, children with high birth order are expected to be at lower risk of asthma than those with low birth order because exposure to their older siblings' infections very early in life is believed to prevent asthma. ${ }^{32} \mathrm{~A}$ study from the Netherlands showed a protective sibling effect on the presence and severity of asthma and atopy; ${ }^{33}$ however, our findings are similar to studies which demonstrated that, although large family size (more than 4 children) is associated with decreased risk of asthma in children, birth order is not involved. ${ }^{29,34}$ We posit that what earlier reports may have indicated as the protective effects of birth order may have been caused by large family size. The reasons for these different observations are unclear, but other unexplored factors may be partly responsible for the observed trend.

Atopy is increasingly recognized as an important factor in the expression of asthma in sub-Saharan Africa, and it is present in approximately $80 \%$ of asthmatic children. ${ }^{35} \mathrm{~A}$ study conducted at 10 -year intervals in young high school children in Ghana demonstrated a greater than $100 \%$ increase in the prevalence of atopy sensitization in asthmatics, which was highest in the urban rich and less common among the urban poor and residents of rural settings. ${ }^{36}$ Although we observed high frequency of 
allergen sensitization (73\%) in asthmatic children, we were unable to show a clear association between prevalence of asthma and atopy that is reflected by positive skin test in addition to increased serum $\operatorname{IgE}$ levels. It is likely that the frequency of atopy sensitization may be high especially in the absence of stool parasitemia in many of the subjects. However, this does not consistently translate to the development of asthma. This lack of relationship between asthma prevalence and atopy has been reported in Australia, where a significant increase in the prevalence of asthma was not associated with concomitant increase in atopy prevalence. ${ }^{35}$

In many rural communities in Africa, the prevalence of chronic intestinal parasitic infection is usually high; and there is growing evidence that intestinal helminthic infection may be protective against atopy and symptoms of asthma. ${ }^{37-38}$ Serum IgE is involved in allergic reactions to environmental allergens and is an important component of the host's protective response. In affluent societies, elevated serum $\operatorname{IgE}$ levels and positive skin sensitivity to allergens that occur in over $30 \%$ of cases are associated with high prevalence of allergic diseases, such as asthma, in up to $12-20 \%$ of cases. ${ }^{38}$ Unlike the observation in affluent countries, the elevated IgE levels due to endemic helminthic infections in most developing countries and associated atopic reactions do not lead to perpetuation of allergic diseases or asthma. ${ }^{38-39}$

In this study, we observed elevated total serum IgE levels, which did not correlate with stool parasitism and were not associated with increased asthma prevalence. Factors responsible for elevated total serum $\operatorname{IgE}$ levels in these schoolchildren are unclear. However, elevated total serum IgE level in blood samples obtained early in childhood have been reported to be predictive of potential development of allergic disorders later in life, ${ }^{40-41}$ raising the possibility of genetic predisposition unrelated to the environmental influence.

In studies conducted in Gambia and Nigeria, atopic reactions, which were present in $35 \%$ and $28 \%$ of cases, translated into an asthma prevalence and wheeze of $3.6 \%$ and $5 \%$, respectively. ${ }^{18,37}$ In the current study, stool parasitism was infrequent in the two groups and did not appear to affect the degree of positive skin reactions to environmental allergens or serum IgE levels. The low prevalence of intestinal parasites in children in this population may probably be linked to deworming drugs, which are readily available over the counter for purchase. While there was correlation between the presence of house dust mites and mouse urine in the home dust sample and eosinophilia, the home dust allergen content did not influence the skin test positivity or serum IgE levels. Despite our observation that sensitization to environmental allergens, such as cats, cockroaches, mango blossom and mouse epithelium, was significantly higher in asthmatics relative to controls, significant correlation to total serum IgE levels was observed only to cockroach mix. This suggests that factors other than sensitization to these common aeroallergens may be driving the increase in asthma prevalence in these communities.

Limitations in this study include the relatively small number of asthmatics in the 13-14 year age group and incomplete dust sampling, especially in control homes. These limitationsreduce our power to draw conclusions about allergens that did not show association with asthma.Additionally, we measured asthma outcomes based on self-reported responses from the validated ISAAC questionnaires without objective measures of asthma such as bronchial hyperresponsiveness (BHR) and lung function test. However, studies have shown that the agreement between self-reported asthma and clinical diagnosis of asthma is substantial. ${ }^{42}$ In one of these studies, the sensitivity and specificity of self-reported asthma was $68 \%$ and $94 \%$ respectively when compared with a clinical diagnosis of asthma. ${ }^{43}$ Therefore, we are confident about the reliability of the ISAAC questionnaire to accurately measure asthma outcomes in this population. Another limitation is the lack of monitoring for indoor air pollution (IAP) from biomass fuels, which is common in rural areas and a known cause of oxidative lung damage and obstructive airway disease. Despite these limitations, this study represents the first detailed efforts to determine factors that affect asthma in children in rural and urban communities in sub-Saharan Africa.

\section{Conclusion}

The observed increase in asthma prevalence in both rural and urban communities in Nigeria is supportive of the global increase in asthma prevalence. While sensitization to aeroallergens such as cat and cockroach and environmental exposure to cigarette smoke was observed, atopy did not appear to play a significant role in asthma in our study cohort for unclear reasons. We speculate that urbanization; especially change in diet, reduced frequency of helminthic infections, and use of biomass fuel for cooking may be important factors in the increasing prevalence of asthma in southwest Nigeria. 
Additional studies focusing on a wider 6-18 year age cohort and examining indoor air quality are needed for better understanding of the interaction between environment and genetics in the expression of asthma in sub-Saharan Africa.

\section{References}

1. Asher MI, Montefort S, Bjorksten B, Lai CK, Strachan DP, Weiland SK, Williams H.

Worldwide time trends in the prevalence of symptoms of asthma, allergic

rhinoconjunctivitis, and eczema in childhood: ISAAC Phases One and Three repeat multicountry cross-sectional surveys. Lancet 2006;368(9537):733-743.

2. Surdu S, Montoya LD, Tarbell A, Carpenter DO. Childhood asthma and indoor allergens in Native Americans in New York. Environ Health 2006;5:22.

3. Brehm JM, Celedon JC, Soto-Quiros ME, Avila L, Hunninghake GM, Forno E, et al. S e r u m vitamin $\mathrm{D}$ levels and markers of severity of childhood asthma in Costa Rica. Am J Respir Crit Care Med 2009; 179(9): 765-771.

4. Litonjua AA, Weiss ST. Is vitamin D deficiency to blame for the asthma epidemic? J Alle rgy Clin Immunol 2007;120(5):1031-1035.

5. Yemaneberhan H, Bekele Z, Venn A, Lewis S, Parry E, Britton J. Prevalence of wheezeand asthma and relation to atopy in urban and rural Ethiopia. Lancet 1997;350(9071):85-90.

6. Devereux G. The increase in the prevalence of asthma and allergy: food for thought. Nat Rev Immunol 2006;6(11):869-874.

7. Lauener RP, Birchler T, Adamski J, BraunFahrlander C, Bufe A, Herz U, et al.

Expression of CD14 and Toll-like receptor 2 in farmers' and non-farmers' children. Lancet 2002;360(9331):465-466.

8. Awotedu AA, Ooyejide C, Ogunlesi A, Onadeko BO. Skin sensitivity patterns to inhalant allergens in Nigerian asthmatic patients. Cent Afr J Med 1992;38(5):187-191.

9. Commey JO, Haddock DR. Skin sensitivity to house dust mite extracts in Ghanaian asthmatics in Accra. Trans $\mathrm{R}$ Soc Trop Med Hyg 1973;67(1):109-111.

10. Addo-Yobo EO, Woodcock A, Allotey A, Baffoe-Bonnie B, Strachan D, Custovic A. Exercise-induced bronchospasm and atopy in Ghana: two surveys ten years apart. PLoS Med 2007;4(2):e70.
11. Ait-Khaled N, Odhiambo J, Pearce N, Adjoh KS, Maesano IA, Benhabyles B, et al. Prevalence of symptoms of asthma, rhinitis and eczema in 13- to 14-year-old children in Africa: the International Study of Asthma and Allergies in Childhood Phase III. Allergy 2007;62(3):247258.

12. Pearce N, Ait-Khaled N, Beasley R, Mallol J, Keil $\mathrm{U}$, Mitchell E, et al. Worldwide trends in the prevalence of asthma symptoms: phase III of the International Study of Asthma and Allergies in Childhood (ISAAC). Thorax 2007;62(9):758-766.

13. Sudhir P, Prasad CE. Prevalence of exerciseinduced bronchospasm in schoolchildren: an urban-rural comparison. J Trop Pediatr 2003;49(2):104-108.

14. Ige OM, Arinola OG, Oluwole O, Falade AG, Falusi AG, Aderemi T, et al. Atopy Is Associated with Asthma in Adults Living in Rural and Urban Southwestern Nigeria. J Asthma 2011;48(9):894-900.

15. Celedon JC, Palmer LJ, Weiss ST, Wang B, Fang $\mathrm{Z}, \mathrm{Xu} \mathrm{X}$. Asthma, rhinitis, and skin test reactivity to aeroallergens in families of asthmatic subjects in Anqing, China. Am J Respir Crit Care Med 2001;163(5):1108-1112.

16. Hamilton RG, Eggleston PA. Environmental allergen analyses. Methods 1997;13(1):53-60.

17. Keeley DJ, Neill P, Gallivan S. Comparison of the prevalence of reversible airways obstruction in rural and urban Zimbabwean children. Thorax 1991;46(8):549-53.

18. Faniran AO, Peat JK, Woolcock AJ. Prevalence of atopy, asthma symptoms and diagnosis, and the management of asthma: comparison of an affluent and a non-affluent country. Thorax 1999;54(7):606-610.

19. Falade AG, Olawuyi JF, Osinusi K, Onadeko BO. Prevalence and severity of symptoms of asthma, allergic rhinoconjunctivitis, and atopic eczema in 6- to 7-year-old Nigerian primary school children: the international study of asthma and allergies in childhood. Med Princ Pract 2004;13(1):20-25.

20. Montealegre F, Fernández B, Delgado A, Fernández L, Román A, Chardón $\mathrm{D}$, et al. Exposure levels of asthmatic children to allergens, endotoxins, and serine proteases in a tropical environment. J Asthma 2004;41(4):485496.

21. Addo-Yobo EO, Custovic A, Taggart SC, Craven M, Bonnie B, Woodcock A. Risk factors African Health Sciences Vol 13 Issue 1 March 2013 
for asthma in urban Ghana. J Allergy Clin Immunol 2001;108(3):363-368.

22. Leung R, Ho P, Lam CW, Lai CK. Sensitization to inhaled allergens as a risk factor for asthma and allergic diseases in Chinese population. $J$ Allergy Clin Immunol 1997;99(5):594-599.

23. Sarpong SB, Karrison T. Sensitization to indoor allergens and the risk for asthma hospitalization in children. Ann Allergy Asthma Immuno 1997;79(5):455-459.

24. Platts-Mills T, Vaughan J, Squillace S, Woodfolk J, Sporik R. Sensitisation, asthma, and a modified Th2 response in children exposed to cat allergen: a population-based cross-sectional study. Lancet 2001;357(9258):752-756.

25. Ownby DR, Johnson CC, Peterson EL. Exposure to dogs and cats in the first year of life and risk of allergic sensitization at 6 to 7 years of age. JAMA 2002;288(8):963-972.

26. Bibi H, Shoseyov D, Feigenbaum D, Nir P, Shiachi R, Scharff S, et al. Comparison of positive allergy skin tests among asthmatic children from rural and urban areas living within small geographic area. Ann Allergy Asthma Immunol 2002;88(4):416-420.

27. Bhalla DK, Hirata F, Rishi AK, Gairola CG. Cigarette smoke, inflammation, and lung injury: a mechanistic perspective. J Toxicol Environ Health B Crit Rev 2009;12(1):45-64.

28. Vassallo R, Tamada K, Lau JS, Kroening PR, Chen L. Cigarette smoke extract suppresses human dendritic cell function leading to preferential induction of Th-2 priming. J Immunol 2005;175(4):2684-2691.

29. Ball TM, Castro-Rodriguez JA, Griffith KA, Holberg CJ, Martinez FD, Wright AL. Siblings, day-care attendance, and the risk of asthma and wheezing during childhood. $N$ Engl J Med 2000;343(8):538-543.

30. von Mutius E, Martinez FD, Fritzsch C, Nicolai T, Reitmeir P, Thiemann HH. Skin test reactivity and number of siblings. BMJ. 1994;308(6930):692-695.

31. Rona RJ, Hughes JM, Chinn S. Association between asthma and family size between 1977 and 1994. J Epidemiol Community Health 1999;53(1):15-19.

32. Strachan DP. Family size, infection and atopy: the first decade of the "hygiene hypothesis". Thorax 2000;55(Suppl 1):S2-S10.

33. Koppelman GH, Jansen DF, Schouten JP, van der Heide S, Bleecker ER, Meyers DA, et al.
Sibling effect on atopy in children of patients with asthma. Clin Exp Allergy 2003;33(2):170175.

34. Goldberg S, Israeli E, Schwartz S, Shochat T, Izbicki G, Toker-Maimon O, et al Asthma prevalence, family size, and birth order. Chest 2007;131(6):1747-1752.

35. Johansson SG, Lundahl J. Asthma, atopy, and IgE: what is the link? Curr Allergy Asthma Rep2001;1(2):89-90.

36. Addo Yobo EO, Custovic A, Taggart SC, Asafo-Agyei AP, Woodcock A. Exercise induced bronchospasm in Ghana: differences in prevalence between urban and rural schoolchildren. Thorax 1997;52(2):161-165.

37. Nyan OA, Walraven GE, Banya WA, Milligan P, Van Der Sande M, Ceesay SM, et al. Atopy, intestinal helminth infection and total serum IgE in rural and urban adult Gambian communities. Clin Exp Allergy 2001;31(11):1672-1678.

38. Yazdanbakhsh M, Kremsner PG, van Ree R. Allergy, parasites, and the hygiene hypothesis. Science 2002;296(5567):490-494.

39. Godfrey RC. Asthma and IgE levels in rural and urban communities of The Gambia. Clin Allergy1975;5(2):201-207.

40. Kaan A, Dimich-Ward H, Manfreda J, Becker A, Watson W, Ferguson A, et al. Cord blood $\mathrm{IgE}$ : its determinants and prediction of development of asthma and other allergic disorders at 12 months. Ann Allergy Asthma Immunol 2000;84(1):37-42.

41. Sadeghnejad A, Karmaus W, Davis S, Kurukulaaratchy RJ, Matthews S, Arshad SH. Raised cord serum immunoglobulin $\mathrm{E}$ increases the risk of allergic sensitisation at ages 4 and 10 and asthma at age 10. Thorax 2004;59(11):936942.

42. Ford ES, Mannino DM, Homa DM, Gwynn, Redd C, Moriarty DG, et al. Self-reported asthma and health-related quality of life: findings from the behavioral risk factor surveillance system. Chest 2003;123(1):119-127.

43. Toren K, Brisman J, Jarvholm B. Asthma and asthma-like symptoms in adults assessed by questionnaires. A literature review. Chest 1993;104(2):600-608. 